\title{
ARTHROSCOPIC MANAGEMENT OF SYNOVIAL CHONDROMATOSIS OF THE KNEE
}

\author{
FINDINGS AND RESULTS IN 18 CASES
}

M. R. COOLICAN, D. J. DANDY

\section{From Newmarket General Hospital and Addenbrooke's Hospital, Cambridge}

\begin{abstract}
We report the results of arthroscopic removal of loose bodies and abnormal synovium from 18 knees with primary synovial chondromatosis. After a mean of three years, six months (range one to 10 years), 14 knees were either symptom-free or had only minor symptoms. Three of these had required two arthroscopic operations. Three patients were improved but not cured and there was one failure. The results were better than the published results of open operation for this condition.

Three patterns of macroscopic appearances were noted: four knees had large lesions covered by normal synovium, 10 had small fragments of cartilage lying in or on the synovium and four had only free fragments of cartilage in the joint cavity but none in, on, or under, the synovium. These three appearances may represent three different disease processes.
\end{abstract}

Primary synovial chondromatosis is a rare monarticular synovial proliferative disease which most commonly affects the knee. Symptoms include pain, swelling, locking, giving way, soft-tissue crepitus and palpable loose bodies. Effusion and synovial thickening are common, radiographs are frequently normal but may show calcified bodies, and the diagnosis is often not made until operation. In joints with a tight capsule, such as the hip, bony erosion may be seen. Secondary synovial chondromatosis, more common and seen in older patients, is diagnosed when articular cartilage is shed from the joint surfaces and embedded in synovium where it may continue to grow. All the patients we report had primary synovial chondromatosis of the knee.

Arthroscopy allows the inspection of joint surfaces in situ and under magnification without surgical disturbance. This has made it possible to propose a morphological classification of primary synovial chondromatosis.

Joint lavage with removal of loose bodies alone is

M. R. Coolican, FRACS, Locum Consultant Orthopaedic Surgeon The Woodlands Hospital, Bristol Road South, Northfield, Birmingham B31 2AP, England.

D. J. Dandy, FRCS, Consultant Orthopaedic Surgeon

Newmarket General Hospital, Exning Road, Newmarket, Suffolk CB8 7JG and Addenbrooke's Hospital, Cambridge CB2 2QQ. England.

Correspondence should be sent to Mr D. J. Dandy.

(C) 1989 British Editorial Society of Bone and Joint Surgery $0301-620 X / 89 / 3113 \$ 2.00$

J Bone Joint Surg [Br] 1989:71-B:498-500. said to be associated with a rapid return of symptoms and most authors recommend synovectomy (Murphy, Dahlin and Sullivan 1962; Enneking 1983; Sim 1985). Open synovectomy of the knee requires extensive dissection and may lead to prolonged joint stiffness as well as recurrence of symptoms, but arthroscopic synovectomy allows diseased synovium to be accurately identified and removed without damage to macroscopically normal tissue.

We report the results of limited arthroscopic surgery in 18 patients with primary synovial chondromatosis treated in the last 10 years, with special reference to classification of the lesions and to recurrence.

\section{PATIENTS AND METHODS}

Eighteen patients with primary synovial chondromatosis were seen in 6,000 consecutive arthroscopies performed by DJD between 1975 and 1987. All these had multiple free or attached cartilaginous bodies. Patients with secondary synovial chondromatosis, degenerative joint disease, or flakes of articular cartilage either floating within the joint or embedded in the synovium were not included.

Arthroscopy was under general anaesthesia and 16 of the 18 patients left hospital by the second postoperative day. All visible loose bodies were removed, the synovium was examined for abnormal areas and these were excised arthroscopically and examined histologically. The appearances of the bodies and the synovium were recorded. For review, 13 patients were interviewed, 
four responded by letter and one was lost to follow-up. Mean follow-up was three years, six months (range one to 10 years).

\section{RESULTS}

The age of the patients ranged from 12 to 66 years (mean 46 years), and the sex incidence was equal. Fourteen patients $(78 \%)$ complained of swelling or a lump, 10 $(55 \%)$ had pain but only two $(11 \%)$ had felt a loose body moving in their knee. Six $(33 \%)$ had a definite history of injury and two $(11 \%)$ complained that the knee had let them down. Five patients ( $28 \%$ ) had loss of full extension and five had soft-tissue crepitus, sometimes described as a 'squidgy feeling'.

Radiography. Five patients had radiographic evidence of synovial chondromatosis, two had medial joint space narrowing without other abnormality, two had softtissue shadows anterior to the tibial eminence. Seven sets of radiographs were normal and two were not available for review.

Arthroscopy. Three distinct arthroscopic appearances were noted:

Deep lesions. In four patients calcified cartilaginous lesions up to $1.5 \mathrm{~cm}$ in diameter were seen lying deep to the synovium. The synovium overlying these lesions was normal on close inspection with the arthroscope and did not contain cartilage fragments. In two patients these lesions were sessile and in the other two pedunculated. The average age of these patients was 54 years (range 35 to 64 years) and three of them had typical radiographic features of synovial chondromatosis.

Superficial lesions. In 10 patients, cartilage fragments from 0.5 to $3 \mathrm{~mm}$ in diameter were seen either attached to synovial fringes or partly covered by synovium. The appearances suggested that the cartilage was being formed within the synovium and shed from it. Histology of specimens showed the classical changes of chondrometaplasia in eight patients and villous hyperplasia in one. The other specimen did not reach the laboratory. The average age of these patients was 44 years (range 12 to 61 years).

Free cartilage fragments. In four knees, no abnormal synovium could be found, but the joints were teeming with cartilage fragments. These were characteristically flattened, lobulated, and were up to $3 \mathrm{~mm}$ in length. Histology in two cases showed that they consisted of cartilage. The number and shape of the fragments were different from the debris seen in the presence of articular cartilage lesions. Despite a careful search, no fragments could be found attached to the synovium in these knees. Histological examination of the synovium showed some villous hyperplasia in three knees, but in the other no abnormal tissue could be found for biopsy. Arthroscopic examination included inspection of the posterior compartments and the popliteus tunnel; no part of the synovial cavity escaped inspection.
Histology. Abnormal synovium was identified and sent for histological study in 13 knees. Eight of these, all with superficial lesions, showed typical cartilage metaplasia within synovium as described by Jaffe (1958); five knees showed the non-specific changes of villous hyperplasia. In four of the other knees, no abnormal tissue was sent to the laboratory because none could be found. Loose bodies from five knees were all shown to consist of cartilage.

Review. There were 13 patients with good results, three with fair results and one failure of the 17 patients reviewed.

Six had remained free of symptoms at an average of 3.5 years after operation (range two to six years). Three of these patients had had a second arthroscopy. Seven patients $(41 \%)$ with an average follow-up of two years (range two to six years) had had minor symptoms such as an ache after heavy use or prolonged squatting, but were essentially symptom-free.

Three patients $(18 \%)$ had had more severe symptoms. One with large deep sessile lesions beneath the synovium was advised to have an arthrotomy because the fragments were not accessible for arthroscopic surgery, but decided that the symptoms did not warrant this. One had moderate degenerative joint disease at arthroscopy and nine years later has pain and stiffness consistent with osteoarthritis, but not the intermittent effusion she suffered before operation. The third has symptoms from a collection of loose bodies in a popliteal cyst, but does not consider the symptoms enough to justify open removal of the cyst.

The one failure had originally presented with a painful and swollen knee with flexion only from 45 to $90^{\circ}$. After two arthroscopic operations to remove synovium and loose bodies, a range of 15 to $130^{\circ}$ was achieved with reduced swelling but pain persisted and the patient was unable to work. After referral to another hospital the patient had a further arthroscopy, an arthrotomy, and later an open synovectomy. Manipulation under anaesthesia to restore movement after the synovectomy had caused a femoral fracture. At the time of review, the femoral fracture had healed but the knee moved only from 10 to $30^{\circ}$ and arthrodesis had been offered.

Re-operation. All patients had initial improvement, but in some symptoms recurred: four patients had a second arthroscopic procedure. Three of these had superficial lesions and one a deep lesion. One had a recurrence of pain and swelling at three years and after further partial synovectomy remained free of symptoms three years later. Another had recurrent loose fragments one year after arthroscopy but remained symptom-free three years after a second arthroscopic operation. A third patient had a recurrence of effusion one year after arthroscopy and remained symptom-free a year after a second arthroscopic irrigation and removal of loose bodies. The fourth patient, our only failure, is described above.

All patients regained their pre-operative range of 
knee movement within two weeks of surgery. There were no cases of infection or haemarthrosis and no thromboembolic complications. No manipulations under anaesthetic were needed to restore movement.

\section{DISCUSSION}

The histological features and natural history of synovial chondromatosis are not agreed. Jaffe (1958), who is credited with the recognition of synovial chondromatosis as an entity, laid down specific histological criteria, including the presence of metaplastic cartilage within the synovial membrane. Milgram (1977) stated that synovial chondromatosis has a phase in which the synovium is histologically and macroscopically normal while Murphy et al. (1962) reported that synovial chondrometaplasia can ordinarily be diagnosed macroscopically. Arthroscopy, which allows synovium to be examined in vivo with magnification similar to that of low-power microscopy, does not solve the problem of diagnostic criteria, but it has highlighted a subgroup of patients hitherto unrecognised and allowed us to classify the condition on a morphological basis.

Three distinct morphological appearances were noted: four patients had large cartilaginous masses lying beneath otherwise normal synovium, in 10 patients the fragments were smaller, lying superficially in or on the synovium and in four patients no cartilage fragments could be found in, on, or beneath the synovium anywhere within the knee. In this last group the histological appearance of villous hyperplasia was seen. Murphy et al. (1962) reported villous hyperplasia in areas adjacent to abnormal synovium. These appearances could well be the result of mechanical irritation by the cartilaginous fragments and not a precursor of metaplasia.

Milgram (1977) in his histopathological study of 30 patients, also noted three separate synovial appearances; he considered that they represented three phases of the same condition, but did not offer any evidence of progression from one phase to the next. The mean age of patients with Milgram Phase II was greater by 15 years than that of patients with Phase III lesions. We believe that the three different appearances are the result of different pathological processes and suggest that free cartilaginous bodies may form within the synovial fluid without any underlying synovial abnormality.
Until recently the conventional treatment for synovial chondromatosis of the knee was open synovectomy, which involved considerable operative trauma and prolonged rehabilitation. Only partial synovectomy is possible via an anterior incision; other incisions are needed for total access and these might endanger other structures. Comparison of open synovectomy with arthroscopic surgery is difficult because few authors have reported long-term results. The early morbidity and complication rate of arthroscopic synovectomy is certainly lower: Murphy et al. (1962) reported moderate or severe loss of movement in $43 \%$ of 31 knees after open operation; five of these required manipulation under anaesthesia. None of our patients lost range of movement after arthroscopic surgery.

Milgram (1977) reported recurrence in three of the 21 cases he reviewed. Jeffreys (1967) had no recurrence in five patients treated by partial synovectomy and 12 managed by arthrotomy and loose body removal alone. Christensen and Poulsen (1975) had five recurrences in 16 patients, eight treated by arthrotomy and loose body removal and eight by synovectomy, but did not say which treatment the patients had received. There seems to be no evidence in the literature to suggest that open operation, with or without synovectomy, has a lower recurrence rate than that in our series. On this basis we consider that arthroscopic removal of loose bodies and any abnormal synovial tissue is the treatment of choice for synovial chondromatosis of the knee.

No benefits in any form have been received or will be received from a commercial party related directly or indirectly to the subject of this article.

\section{REFERENCES}

Christensen JH, Poulsen JO. Synovial chondromatosis. Acta Orthop Scand 1975:46:919-25.

Enneking WF. Musculoskeletal tumor surgery. New York: Churchill Livingstone, 1983.

Jaffe HL. Tumors and tumorous conditions of the bones and joints. London: Henry Kimpton, 1958.

Jefireys TE. Synovial chondromatosis. J Bone Joint Surg [Br] $1967 ; 49-B: 530-4$.

Milgram JW. Synovial osteochondromatosis: a histopathological study of thirty cases. J Bone Joint Surg [Am] 1977;59-A:792-801.

Murphy FP, Dahlin DC, Sullivan CR. Articular synovial chondromatosis. J Bone Joint Surg [Am] 1962;44-A :77-86.

Sim FH. Synovial proliferative disorders: role of synovectomy. Arthroscopy 1985:1:198-204. 